\title{
Significant reduction of symptomatic headache by medical marijuana - Case report
}

\author{
Jacek Kurzepa ${ }^{1, A-F} \oplus$, Wiktor Wezgraj2, ${ }^{2, \mathrm{E}-\mathrm{F} \oplus}$, Dorota Luchowska-Kocot ${ }^{1, \mathrm{E}-\mathrm{F} \oplus}$ \\ ${ }^{1}$ Department of Medical Chemistry, Medical University, Lublin, Poland \\ ${ }^{2}$ Terapie Cannabium, Lublin, Poland \\ A - Research concept and design, B - Collection and/or assembly of data, C - Data analysis and interpretation, \\ $D$ - Writing the article, E-Critical revision of the article, F- Final approval of the article
}

Kurzepa J, Wezgraj W, Luchowska-Kocot D. Significant reduction of symptomatic headache by medical marijuana. Case report. J Pre-Cin Clin Rs. 2021; 15(4): 162-164. doi: 10.26444/jpccr/142773

\begin{abstract}
Despite the limited number of large clinical trials on the positive therapeutic effect of medical marijuana, the several thousand-year history of using cannabis in medicine and numerous reports allow the conclusion that cannabis preparations have a great therapeutic potential. The report presents the clinical case of a 35-year-old female patient treated with medical marijuana preparations due to persistent headache following neurosurgical resection of a brain tumour. Therapy with medical marijuana was started 3 years after surgery. Headache occurred several times a day and responded poorly to NSAIDs, which resulted in the patient often giving-up pharmacological treatment. The applied treatment with dried cannabis with high THC content taken by vaporization in a finally dose of $0.1 \mathrm{~g}$ twice a day showed a significant reduction in pain by 7-9 on the NRS within the 3 months of therapy. This observation suggests a significant analgesic effect of cannabis in the treatment of symptomatic headaches.
\end{abstract}

\section{Key words}

THC, marijuana, pain, symptomatic headache

\section{INTRODUCTION}

The therapeutic potential of cannabis has been known to mankind for over 5,000 years. Cannabis Sativa L. is a source of several hundred compounds with more-or-less known biological properties. The most studied compound is (-) - trans- $\Delta$ 9-tetrahydrocannabinol (THC) - which is mainly produced in the flowers and leaves of the plant. It is the primary compound with psychoactive properties; therefore, its legal content in over-the-counter cannabis preparations in many countries, including Poland, may not exceed $0.2 \%$. Another phytocannabinoid, cannabidiol (CBD), also possesses anti-inflammatory and potential anticonvulsant properties without the psychoactive effects of THC [1]. Furthermore, CBD is capable of antagonizing the psychoactive effects of THC [2]. Cannabis also contains a large amount of other phytocannabinoids, terpenes, flavonoids, which when working together seem to enhance each other's therapeutic properties, the so-called entourage effect potentially occurring in cannabis, although this is denied by some researchers $[3,4]$.

The target for phytocannabinoids in animals is the endogenous cannabinoid system, which includes 2 types of cannabinoid receptors, $\mathrm{CB} 1$ and $\mathrm{CB} 2$, activated by a few of the endogenous cannabinoids, derivatives of arachidonic acid. THC, a partial agonist of CB1 and CB2, is an analog of one of them - anandamide [5]. THC is responsible for most of the pharmacological effects of cannabis, in addition to the psychoactive effects, as well as being an analgesic, antiinflammatory, antioxidant and muscle relaxant [6].

Address for correspondence: Jacek Kurzepa, Department of Medical Chemistry, Medical University, Chodzki 4a, 20-093 Lublin, Poland

E-mail: jacekkurzepa@umlub.pl

Received: 29.08.2021; accepted: 01.10.2021; first published: 15.10.2021
Due to the analgesic properties of THC and CBD, both of these agents are used in anti-pain therapy. Previous observations noticed that agonists of $\mathrm{CB} 1$ receptors (as THC) proved to be of greater therapeutic benefit in treating various types of headache [7]. Moreover, retrospective analysis provided that patients taking cannabis with high THC to CBD ratio, reported a significantly higher occurrence of overall headache profile improvement than patients receiving cannabis with a lower THC content [8].

Phytocannabinoids are naturally acidic (THCA, CBDA), which do not show the expected biological activity. Activation occurs through the decarboxylation process, increasing by high temperature. Therefore, heating the cannabis plant is essential for obtaining its therapeutic properties [9]. Heating that leads to activation of phytocannabinoids can be achieved by vaporization. Previous studies revealed that inhaled (vaporized as well as smoked) cannabis is effective in reducing chronic pain. In addition, the literature shows that inhaled cannabis seems to be more tolerable and predictable than oral cannabinoids [10].

This case report shows the use of cannabis in the treatment of symptomatic headache.

\section{CASE REPORT}

A 35-year-old female patient, 3 years after neurosurgical resection of an intracranial tumour in the right temporal region, was admitted to Neurological Outpatient Clinic in order to consider starting medical marijuana therapy due to chronic, severe headache.

Medical history. The only symptoms of the tumour presence were chronic headache occurring for many years, with gradual increase a few months before the resection of the tumour. 


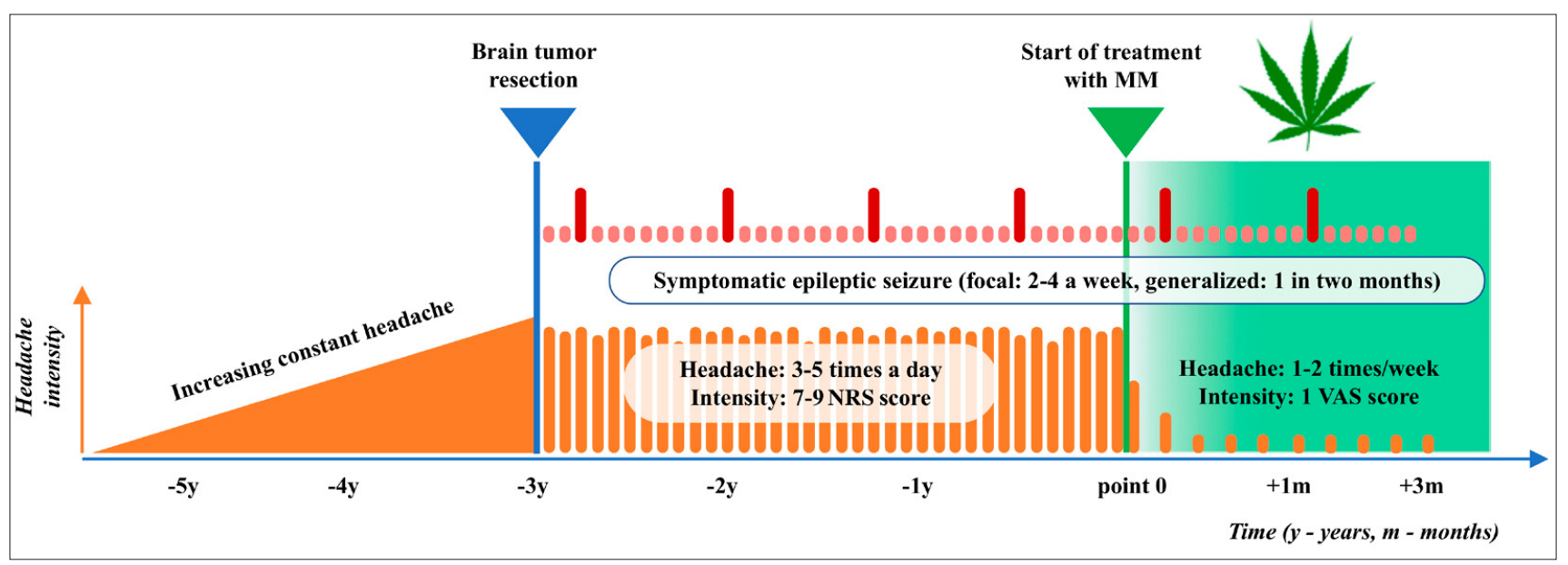

Figure 1. Clinical status of the described patient before and after inclusion in medical marijuana treatment (point 0 ). Since the resection of the intracranial tumour (3 years earlier), the patient had experienced severe headaches and epileptic seizures (focal and, less frequently, generalized). In the 4-month follow-up period after starting treatment with marijuana (a dose of $0.2 \mathrm{~g}$ daily of dried Cannabis), headaches were radically reduced. The frequency of seizures had not changed.

Imaging studies showed the presence of a $2 \mathrm{~cm} \times 5 \mathrm{~cm}$ tumour in the temporal lobe. The patient was qualified for tumour resection, which proceeded without complications. There was no radiotherapy or chemotherapy after the surgery. Histopathological examination revealed the presence of cells of astroglial origin, and immunohistochemistry showed weak labeling for GFAP (+) and Ki-67 (+). After resection of the tumor the patient developed symptomatic epilepsy, both localization-related and generalized seizures, and chronic severe headaches. The epilepsy attacks occurred 2-4 times a week, mainly in the left upper limb, opposite the postoperative bed. The generalized seizures occurred once every 1-2 months. Additionally, during the seizures, the patient experienced anxiety attacks. The severe headache began with attacks lasting about 1-2 hours, several times a day, pulsating, pressing and covering the entire head. The patient rated the typical pain intensity at 7-9 points (consistent with the Numeric Rating Scale). Due to the epilepsy the patient received carbamazepine $0.4 \mathrm{~g}$ twice a day, together and lacosamide $0.1 \mathrm{~g}$ three times a day. There had been an attempt to use CBD oil in the past, but did not produce any reduction in seizure frequency. Anxiety attacks was treated with low doses of perazin ( $25 \mathrm{mg}$ a day) and escitalopram (20 mg a day). According to the patient's report, the best headache control was achieved by taking high doses of paracetamol, up to $4 \mathrm{~g}$ a day. Due to a history of increased heart rate, she was given metoprolol $50 \mathrm{mg}$ daily.

Baseline visit - initiation of cannabis treatment. Headache was the main symptom reported by the patient at baseline visit, which significantly decreased the quality of life. The patient was qualified for Cannabis sativa L. treatment in gradually increasing doses. She received a dried whole flower with high THC content $(\sim 20 \%)$ and low CBD content (up to $1 \%)$ for vapourization. The patient was informed about the method of taking the herbs and about the vapourizsation technique. Treatment was started with a dose of $50 \mathrm{mg} /$ evening, after which the dose was gradually increased by $50 \mathrm{mg}$ every 3 days to the target dose of $100 \mathrm{mg}$, twice a day (from the $10^{\text {th }}$ day of treatment).

$\mathbf{1}^{\text {st }}$ follow-up visit. 30 days after the initiation visit the patient reported significant reduction in headache intensity (NRS
Table 1. Characteristics of drugs taken during follow-up visits

\begin{tabular}{llll}
\hline Drugs & Baseline visit & 1st follow-up & 2nd follow-up \\
\hline Time & 0 & +1 month & +3 months \\
\hline $\begin{array}{l}\text { Cannabis } \\
\text { Sativa L. }\end{array}$ & $\begin{array}{l}\text { Start of } \\
\text { treatment }\end{array}$ & $\begin{array}{l}0.2 \mathrm{~g} \text { of dried } \\
\text { whole flower a day }\end{array}$ & $\begin{array}{l}0.2 \mathrm{~g} \text { of dried whole } \\
\text { flower a day }\end{array}$ \\
\hline Paracetamol & up to $4 \mathrm{~g}$ a day & 0.5 -1.0 g per week & $0.5-1.0 \mathrm{~g}$ per week \\
\hline Carbamazepine & $0.4 \mathrm{~g}$ twice a day & $0.4 \mathrm{~g}$ twice a day & 0.4 twice a day \\
\hline Lacosamide & $\begin{array}{l}0.1 \mathrm{~g} \text { three } \\
\text { times per day }\end{array}$ & $\begin{array}{l}0.1 \mathrm{~g} \text { three times } \\
\text { per day }\end{array}$ & - \\
\hline Lamotrigine & - & - & $0.2 \mathrm{~g}$ two times per day \\
\hline Perazin & $\begin{array}{l}25 \mathrm{mg} \text { once } \\
\text { daily }\end{array}$ & $25 \mathrm{mg}$ once daily & $25 \mathrm{mg}$ once daily \\
\hline Escitalopram & $20 \mathrm{mg}$ & $20 \mathrm{mg}$ & $10 \mathrm{mg}$ \\
\hline Metoprolol & $50 \mathrm{mg}$ daily & $50 \mathrm{mg}$ daily & $50 \mathrm{mg}$ daily \\
\hline
\end{tabular}

score -1 point) which resulted in a significant improvement in the quality of life. The frequency and the character of epileptic seizures, however, had not changed during the treatment with cannabis.

$2^{\text {nd }}$ follow-up visit. 90 days after baseline, the patient reported a continued reduction in headache (NRS score - 1 point), with no clinical change compared to the first follow-up visit. To further improve the quality of life, the treating epilepsy doctor had switched from lacosamide to lamotrigine. Escitalopram was reduced to $10 \mathrm{mg}$ a day. The remaining treatment remained unchanged compared to the first followup. The cannabis treatment was maintained at a dose of 0.2 g a day.

\section{DISCUSSION}

Cannabinoids appear to have various potential medical uses, including pain control. Earlier reports indicate a significant role of the endocannabinoid system in the pain modification of various etiologies [11]. The positive effect of cannabinoids was shown in controlling neuropathic pain, allodynia, rebound headache, and chronic non-cancer pain, but their influence on acute or visceral pain was uncertain [12]. 
Chronic pain, together with chemotherapy-induced nausea and vomiting, are symptoms with the best documented sensitivity to treatment with cannabis preparations. A meta-analysis evaluating inhaled cannabis in the treatment of neuropathic pain compared with placebo, assessed its effectiveness at $3.22(95 \% \mathrm{CI}=1.59-7.24)[13,14]$. Several studies noted that the mean number of patients who reported a pain reduction of at least $30 \%$ was higher with cannabinoids than with placebo [15].

The presented case report shows that symptomatic headache can be effectively treated with Cannabis Sativa L. with high THC content administrated at a dose $0.1 \mathrm{~g}$ twice daily through vaporization method. Cannabis vaporization suppress respiratory toxins by heating cannabis to a temperature where cannabinoids evaporate (typically around $180-190^{\circ} \mathrm{C}$ ), but below the point of combustion where smoke and associated toxins are produced (near $230^{\circ} \mathrm{C}$ ). In addition, during vaporization, all the compounds contained in the cannabis, which reach the boiling point at the applied temperature are inhaled, allows them to work together (potential entourage effect) [16].

The observed analgesic effect of cannabinoids may be a result of both their known influence on the cannabinoid system, as well as their modifying effect on other drugs that potentially posses the anti-headache properties. Because the patient also received anti-epileptic drugs and beta blockers that can be used for headache treatment (e.g. migraine), the analgesic effect of cannabinoids could therefore potentially be caused by boosting the effect of the drugs taken so far.

When analyzing the effects of cannabinoids, one should bear in mind their influence on the excitability of neurons. Evidence from dozens of experimental studies in 6 species of animals shows that THC has anti-convulsant activity in over $60 \%$ of them, while over $30 \%$ of studies noticed no effect on the occurrence of seizures. Only one study indicated a pro-convulsive effect of THC; at the same time, no studies have shown the pro-convulsive effects of CBD [17]. In the described patient, a daily dose of 0.2 grams of Cannabis sativa did not increase the frequency of epileptic seizures. The patient also did not observe any reduction in seizure frequency, indicating no effect of the therapy on the seizures.

In presenting the positive effects of cannabinoids it is worth noting that some reports indicate the anti-tumour activity of THC, also in relation to human glioblastoma cells. However, this observation requires further research and the current state of knowledge does not allow us to determine whether the observed effect is clinically significant $[18,19]$.

In conclusion, the presented clinical case suggests a significant effect of cannabis on the reduction of severe symptomatic headache.

\section{REFERENCES}

1. Costa B, Trovato AE, Comelli F, et al. The non-psychoactive cannabis constituent cannabidiol is an orally effective therapeutic agent in rat chronic inflammatory and neuropathic pain. Eur J Pharmacol. 2007; 556: 75-83. 10.1016/j.ejphar.2006.11.006

2. Thomas A, Baillie GL, Phillips AM, et al. Cannabidiol displays unexpectedly high potency as an antagonist of CB1 and CB2 receptor agonists in vitro. Br J Pharmacol. 2007; 150: 613-623. 10.1038/ sj.bjp. 0707133

3. Ferber SG, Namdar D, Hen-Shoval D, et al. The "Entourage Effect": Terpenes Coupled with Cannabinoids for the Treatment of Mood Disorders and Anxiety Disorders. Curr Neuropharmacol. 2020; 18(2): 87-96. doi: 10.2174/1570159X17666190903103923

4. Cogan PS. The 'entourage effect' or 'hodge-podge hashish': the questionable rebranding, marketing, and expectations of cannabis polypharmacy. Expert Rev Clin Pharmacol. 2020; 13(8): 835-845. doi: 10.1080/17512433.2020.1721281

5. Amin MR, Ali DW. Pharmacology of Medical Cannabis. Adv Exp Med Biol. 2019; 1162: 151-165. doi: 10.1007/978-3-030-21737-2_8

6. Vučković S, Srebro D, Vujović KS, et al. Cannabinoids and Pain: New Insights From Old Molecules. Front Pharmacol. 2018; 13(9): 1259. doi: 10.3389/fphar.2018.01259

7. Lochte BC, Beletsky A, Samuel NK, Grant I. The Use of Cannabis for Headache Disorders. Cannabis Cannabinoid Res. 2017; 2(1): 61-71. doi: 10.1089/can.2016.0033

8. Mechtler L, Bargnes V, Hart P, et al. Medical Cannabis for Chronic Migraine: A Retrospective Review (P3.10-015). Neurology. 2019; 92: P3.10-015.

9. Citti C, Pacchetti B, Vandelli MA, et al. Analysis of cannabinoids in commercial hemp seed oil and decarboxylation kinetics studies of cannabidiolic acid (CBDA). J Pharm Biomed Anal. 2018; 5; 149: 532-540. doi: 10.1016/j.jpba.2017.11.044. Epub 2017 Nov 20

10. Romero-Sandoval EA, Kolano AL, Alvarado-Vázquez PA. Cannabis and Cannabinoids for Chronic Pain. Curr Rheumatol Rep. 2017; 19(11): 67. doi: 10.1007/s11926-017-0693-1

11. Woodhams SG, Chapman V, Finn DP, et al. The cannabinoid system and pain. Neuropharmacology. 2017; 15(124): 105-120. doi: 10.1016/j. neuropharm.2017.06.015

12. Pergolizzi JV Jr, Lequang JA, Taylor R Jr, et al. The role of cannabinoids in pain control: the good, the bad, and the ugly. Minerva Anestesiol. 2018; 84(8): 955-969. doi: 23736/S0375-9393.18.12287-5. Epub 2018 Jan 16.

13. Andreae MH, Carter GM, Shaparin N, et al. Inhaled Cannabis for Chronic Neuropathic Pain: A Meta-analysis of Individual Patient Data. J Pain. 2015; 16(12): 1221-1232. doi: 10.1016/j.jpain.2015.07.009

14. Abrams DI. The therapeutic effects of Cannabis and cannabinoids: An update from the National Academies of Sciences, Engineering and Medicine report. Eur J Intern Med. 2018; 49: 7-11. doi: 10.1016/j. ejim.2018.01.003. Epub 2018 Jan 9.

15. Likar R, Nahler G. The use of cannabis in supportive care and treatment of brain tumor. Neurooncol Pract. 2017; 4(3): 151-160. doi: 10.1093/nop/ npw027. Epub 2017 Jan 18.

16. Ferber SG, Namdar D, Hen-Shoval D, et al. The "Entourage Effect": Terpenes Coupled with Cannabinoids for the Treatment of Mood Disorders and Anxiety Disorders. Curr Neuropharmacol. 2020; 18(2): 87-96. doi: 10.2174/1570159X17666190903103923

17. Rosenberg EC, Tsien RW, Whalley BJ, Devinsky O. Cannabinoids and Epilepsy. Neurotherapeutics. 2015; 12(4): 747-68. doi: 10.1007/ s13311-015-0375-5

18. Hart S, Fischer OM, Ullrich A. Cannabinoids induce cancer cell proliferation via tumor necrosis factor alpha-converting enzyme (TACE/ ADAM17)-mediated transactivation of the epidermal growth factor receptor. Cancer Res. 2004; 64(6): 1943-50. doi: 10.1158/0008-5472. can-03-3720

19. Galanti G, Fisher T, Kventsel I, et al. Delta 9-tetrahydrocannabinol inhibits cell cycle progression by downregulation of E2F1 in human glioblastoma multiforme cells. Acta Oncol. 2008; 47(6): 1062-70. doi: 10.1080/02841860701678787 